The use of costal cartilage graft during rhinoplasty entails two main problems - warping and visibility. ${ }^{[2]}$ When costal cartilage graft is being used to make various struts (particularly the dorsal strut), the sharp edges need to be rounded off to decrease the chances of visibility of the graft underneath the thin dorsal nasal skin. ${ }^{[3,4]}$ The inferior surface of the graft also needs to be straight to conform to the surface on which it rests.

Rhinoplasty surgeons have used various techniques for this purpose. Traditionally, a No. 11 blade has been used to achieve this and is fraught with risk of accidentally cutting off a large piece or splintering and eventually producing non-uniform smoothening of the graft. Some surgeons have used flint paper for rubbing the graft to smoothen out the edges. Such usage carries the risk of introducing particulate matter into the graft which may be carried into the nose and cause various problems.

The authors use glass polishing diamond disc for this purpose [Figures 1 and 2]. This instrument is a circular disc with a hole in the centre. It has diamond crystals attached in a circular band akin to the diamond burr. Generally, the hole in the centre receives the head of the motor on which the disc is mounted and it is then used for etching or frosting of glass and smoothening of sharp edges of the glass sheets. The disc is cheap (around Rs. 200) and is easily available commercially. It can be autoclaved and kept as a part of the rhinoplasty set. It does not leave behind any particulate matter and is biologically inert. Furthermore, the diamond burr is a part of standard usage for dermabrasion, is time tested and is found to be safe for use in biological and surgical

\title{
Ingenious technique of smoothening costal cartilage graft by glass polishing disc
}

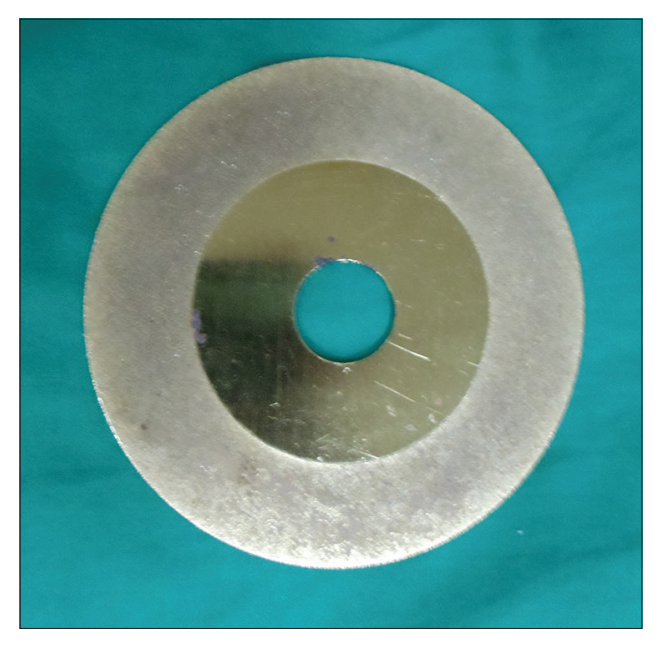

Sir,

Costal cartilage grafts are commonly used for restructuring of the nasal skeleton during rhinoplasty. Depending on various deficiencies, different modifications of the grafts used are spreader graft, columellar strut, septal extension graft and dorsal strut. ${ }^{[1]}$

Figure 1: Diamond crystal coated glass polishing disc 


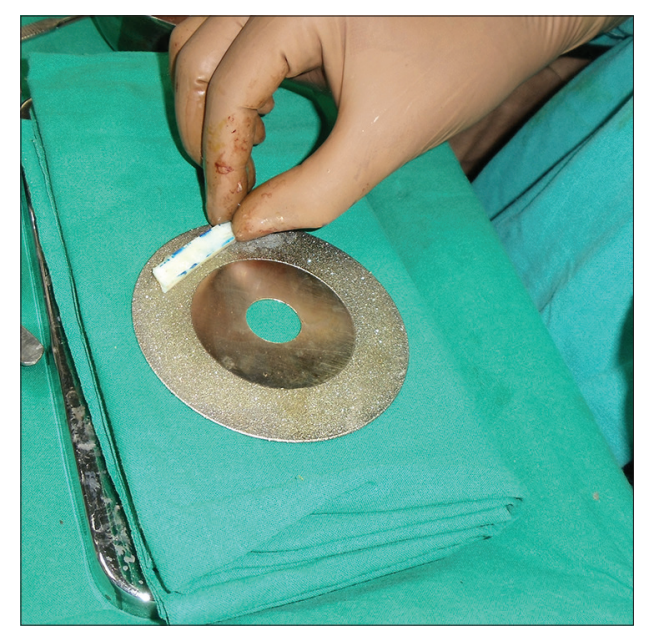

Figure 2: Costal cartilage graft smoothening using glass polishing disc

settings. Hence, the glass polishing disc is expected to behave similarly.

Diamond burrs have also been used for this purpose by some; however, it is very easy to hold the cartilage in the hand and rub it against a static rough surface by which precision rounding of edges and flattening of dorsal surface can be achieved with a very good control over the graft, as compared to using a burr mounted on motor (with the cartilage piece kept static). In addition, rubbing with a file, while holding the cartilage in hand, is difficult and carries the risk of breaking the cartilage.

The authors have been using the instrument for the last 7 years now and have used it for almost 250 patients of rhinoplasty to smoothen the costal cartilage graft with satisfactory results. Thus, the disc can be considered as an important adjunct to the rhinoplasty surgeon's armamentarium.

\section{Financial support and sponsorship}

Nil.

\section{Conflicts of interest}

There are no conflicts of interest.

\section{Kapil Agrawal, Raghav Shrotriya}

Department of Plastic and Reconstructive Surgery, KEM Hospital, Mumbai, Maharashtra, India

Address for correspondence: Dr. Raghav Shrotriya, Department of Plastic Surgery, Gynaecology Wing, $2^{\text {nd }}$ Floor, KEM Hospital, Parel, Mumbai - 400012 , Maharashtra, India. E-mail:dr.raghav.s@gmail.com

\section{REFERENCES}

1. Agrawal KS, BachhavM, Shrotriya R. Namaste (counterbalancing) technique: Overcoming warping in costal cartilage. Indian J Plast Surg 2015;48:123-8.

2. Kim DW, Shah AR, Toriumi DM. Concentric and eccentric carved costal cartilage: A comparison of warping. Arch Facial Plast Surg 2006;8:42-6.

3. Agrawal K, Shrotriya R, Bachhav M. Diced cartilage under perichondrial carpet with reinforcement (DCUP) technique for nasal dorsal augmentation. J Cleft Lip Palate Craniofac Anomal 2016;3:3-8.

4. Tastan E, Yücel ÖT, Aydin E, Aydogan F, Beriat K, Ulusoy MG. The oblique split method: A novel technique for carving costal cartilage grafts. JAMA Facial Plast Surg 2013;15:198-203.

This is an open access article distributed under the terms of the Creative Commons Attribution-NonCommercial-ShareAlike 3.0 License, which allows others to remix, tweak, and build upon the work non-commercially, as long as the author is credited and the new creations are licensed under the identical terms.

\begin{tabular}{|l|l|}
\multicolumn{2}{|c|}{ Access this article online } \\
\hline Quick Response Code: & Website: \\
\hline & www.ijps.org \\
\cline { 2 - 2 } & Dol: \\
\hline
\end{tabular}

How to cite this article: Agrawal K, Shrotriya R. Ingenious technique of smoothening costal cartilage graft by glass polishing disc. Indian J Plast Surg 2016;49:288-9. 